DOI: $\underline{\text { https://doi.org/10.24867/09BE08Stupar }}$

\title{
REGULACIJA FREKVENCIJE POMOĆU UREĐAJA ZA SKLADIŠTENJE ENERGIJE U IZOLOVANIM ELEKTROENERGETSKIM SISTEMIMA
}

\section{FREQUENCY CONTROL SUPPORT IN ISOLATED POWER SYSTEMS USING ENERGY STORAGE DEVICES}

\author{
Vanja Stupar, Fakultet tehničkih nauka, Novi Sad
}

\begin{abstract}
Oblast - ELEKTROTEHNIKA I RAČUNARSTVO
Kratak sadržaj - U radu je razmatrana primena sistema za skladištenje energije $u$ cilju podrške regulacije frekvencije u izolovanim elektroenergetskim sistemima sa niskom rotacionom inercijom. Osnovni zadatak dinamičke podrške za kontrolu frekvencije je da se iskoristi prednost brzog odziva sistema za skladištenje energije kako bi se podržale generatorske jedinice usled nedostatka proizvodnog kapaciteta, obezbeđujući na taj način poboljšanje stabilnosti sistema.
\end{abstract}

Ključne reči: Sistemi za skladištenje energije, Regulacija frekvencije, Izolovani sistemi, Dvosmerni tok aktivne energije, Trofazni naponski invertori

Abstract - This paper cosiders integration of energy storage system in islanded power systems with low rotational inertia to support frequency regulation. The main goal of dynamic frequency control support is to take advantage of fast-acting energy storage devices to support generation assets due to deficency of production capacity, ensuring stable operation of power systems.

Keywords: Energy storage systems, Frequency control, Isolated power systems, Bi-directional power flow control, Three phase voltage source inverters

\section{UVOD}

Elektroenergetski sistemi (EES) rade na određenoj frekvenciji i zahtevaju ravnotežu između proizvodnje i potrošnje električne energije, jer je skladištenje energije u velikim količinama veoma skupo i teško sa tehničkog stanovišta. Kako se frekvencija sistema koristi kao referentna veličina za procenu debalansa između aktivne snage proizvodnje i potrošnje električne energije, veća odstupanja frekvencije od nominalne vrednosti nisu poželjna jer mogu uticati na prekide napajanja u sistemu.

U slučaju velikih poremećaja, u interkonektivnim EES postoje razni načini da se sistem zaštiti od kolapsa. Sa druge strane, kada se posmatraju izolovani EES, narušavanje bilansa aktivnih snaga može značajno da utiče i na rad generatora i na promenu frekvencije $u$ sistemu. Niska inertnost sistema i nedostatak povezanosti sa drugim EES čine ovaj sistem veoma osetljivim na poremećaje. Konvencionalne tehnologije koje se koriste za proizvodnju energije nisu uvek sposobne da odgovore dovoljno brzo i spreče neprihvatljivo niske frekvencije.

\section{NAPOMENA:}

Ovaj rad proistekao je iz master rada čiji mentor je bio dr Željko Popović, docent.
Stoga, primarna regulacija frekvencije predstavlja kritičan problem kada se radi o izolovanim sistemima. Kao rezultat toga, velika pažnja posvećena je održavanju kvaliteta napajanja potrošača, pouzdanosti i stabilnosti EES-a. U cilju prevazilaženja pomenutih problema $u$ izolovanim EES mogu se koristiti neki od sledećih resursa:

- Upravljanje opterećenjem,

- Angažovanje rotirajuće rezerve i

- Upotreba sistema za skladištenje energije.

Sistemi za skladištenje energije prepoznati su kao jedno od najefikasnijih rešenja za povećanje energetske efikasnosti, poboljšanje pouzdanosti i stabilnosti EES-a, rešavanje problema vršnog opterećenja i uspostavljanje ravnoteže između proizvodnje i potrošnje.

Ovaj rad se bavi analizom i modelovanjem sistema za skladištenje energije kako bi se procenio uticaj na regulaciju frekvencije. Na primeru realnog izolovanog EES-a, kojeg karakteriše česta upotreba sistema sa odsecanje opterećenja, prikazan je uticaj sistema za skladištenje energije različitih snaga na promenu frekvencije u sistemu.

\section{PROBLEMI U IZOLOVANIM ELEKTROENERGETSKIM SISTEMIMA}

Rad EES-a remeti čitav niz poremećaja, od malih promena opterećenja koja se dešavaju neprekidno, do ispada elemenata sistema i kratkih spojeva. Gubitak generatorske jedinice generalno je štetniji od dodatnog opterećenja, jer se u drugom pomenutom slučaju u obzir uzima inercija svih povezanih grupa, dok ispad generatora, pored prouzrokovane neravnoteže, ima za posledicu značajan pad inertnosti sistema.

Za stabilan rad EES-a neophodna je kontrola frekvencije sistema, koja se zasniva na ravnoteži između proizvodnje i potrošnje. Poremećaji u ovom bilansu nadoknađuju se iz kinetičke energije sinhronih generatora $E_{k}$ koji su povezani na mrežu, izazivajući varijaciju frekvencije $f$ od svoje zadate vrednosti $f_{n}$. Promena frekvencije u vremenu može se definisati sledećim izrazom [1]:

$$
\frac{d f}{d \mathrm{t}}=f_{n} \cdot \frac{P_{m}-P_{e}}{2 \cdot E_{k}}=f_{n} \cdot \frac{\Delta P^{p u}}{2 \cdot H},
$$

gde $P_{m}$ i $P_{e}$ predstavljaju snagu proizvodnje i potrošnje, $\Delta P^{p u}$ debalans aktivne snage $\mathrm{u}$ sistemu u relativnim jedinicama, a $H$ konstantu inercije sinhrone mašine.

Brzina promene frekvencije sistema zavisi od količine raspoložive trenutne rezerve, a samim tim i od inertnosti 
sistema. Kako je inercija izolovanog sistema relativno mala u poređenju sa velikim interkonekcijama, poremećaji u sistemu imaće veći uticaj na brzinu promenu frekvencije. Prethodna jednačina pokazuje da je brzina promene frekvencije obrnuto srazmerna inerciji sistema što je niža inercija, to je veća brzina promene frekvencije za dati poremećaj u sistemu.

Većina proizvodnih jedinica koje se koriste u ostrvskim mrežama ne mogu da odgovore dovoljno brzo da spreče veliki pad frekvencije u slučaju velikih poremećaja. Uprkos naporima da se obezbedi dovoljna količina primarne rezerve u ovakvim sistemima, aktiviranje sistema za automatsko odsecanje opterećenja (engl. Automatic Load Shedding) gotovo je neizbežno. Automatsko odsecanje opterećenja predstavlja poslednji vid zaštite koji treba preduzeti, kako bi se izbegao raspad sistema [2, 3]. Stoga, prekidi napajanja potrošača se mogu izbeći korišćenjem brzog delovanja uređaja za skladištenje energije, o kojima će biti više reči u nastavku.

\section{ULOGA SISTEMA ZA SKLADIŠTENJE ENERGIJE}

Skladištenje energije pruža mnoštvo korisnih usluga i uštedu troškova brojnim EES, posebno izolovanim mrežama koje karakteriše relativno česta upotreba sistema za odsecanje opterećenja. Strateški postavljeni sistemi za skladištenje energije širom EES-a mogu poboljšati performanse i pouzdanost celokupne mreže, unaprediti integrisanje obnovljivih izvora energije, uravnotežiti proizvodnju i potrošnju električne energije i osigurati da energija bude lako dostupna kada su primarni izvori energije u kvaru. Stoga, skladištenje energije predstavlja značajnu prednost celokupnog EES-a, od proizvodnje, prenosa i distribucije, pa sve do neposrednih korisnika.

Sistemi za skladištenje energije koriste pretvarače bazirane na energetskoj elektronici u procesu konverzije energije. Ovi sistemi omogućuju sledeće sistemske usluge [4]:

- Naponsku podršku,

- Podršku frekvenciji sistema,

- Izravnavanje opterećenja i

- Pokrivanje vršnog opterećenja.

U daljem radu pažnja će biti posvećena uticaju sistema za skladištenje energije na regulaciju frekvencije nakon nastalog debalansa aktivne snage u sistemu. U ovom radu razmatrane su litijum-jonske baterije kao jedan od najprikladnijih sistema za skladištenje energije koji se koriste za regulisanje frekvencije.

\section{DINAMIČKA PODRŠKA SISTEMA ZA SKLADIŠTENJE ENERGIJE ZA REGULACIJU FREKVENCIJE}

Dinamička podrška za kontrolu frekvencije je napredna usluga koju sistemi za skladištenje mogu da obezbede izolovanim mrežama. Sastoji se od injektiranja ili apsorbovanja energije nakon poremećaja, kako bi se podržale generatorske jedinice. Usled nedostatka generatorskih kapaciteta, u kratkom vremenskom periodu deo energije se snabdeva od strane sistema za skladištenje energije. Glavni cilj primene sistema za skladištenje energije je da se obezbedi optimalna kontrola frekvencije i na taj način smanji česta upotreba sistema za automatsko odsecanje opterećenja u ostrvskim sistemima. U nastavku je predložen model celokupnog sistema sa priključenim uređajem za skladištenje energije i opisane su upravljačke strukture koje su primenjene $\mathrm{u}$ radu.

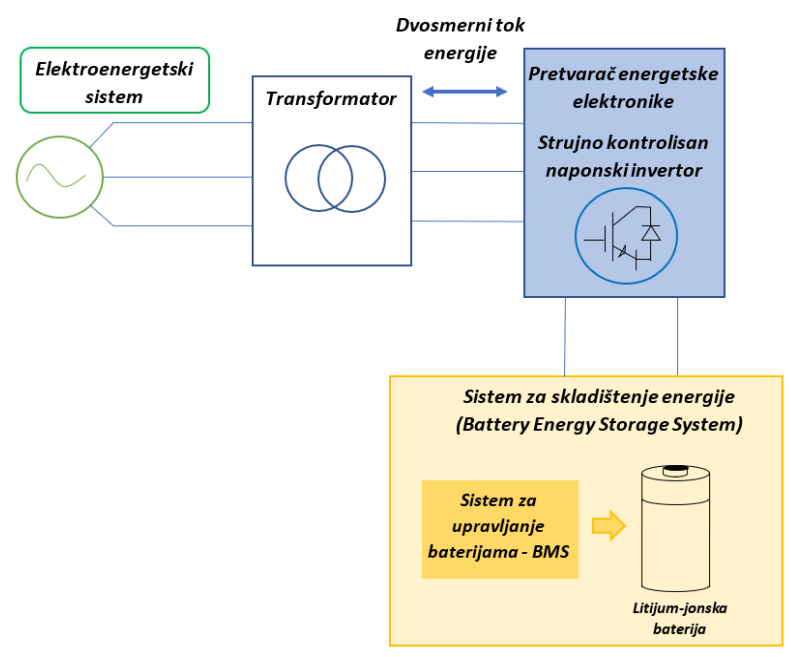

Slika 1. Sistem sa povezanim sistemom za skladištenje energije putem trofaznog naponskog invertora

\subsection{Osnovne komponente sistema}

Celokupan sistem, koji je prikazan na slici 1, se sastoji od sledećih elemenata:

- Povezanog sistema za skladištenje energije (engl.

Battery Energy Storage System - BESS),

- Sistema za upravljanje baterijama (engl. Battery

Management System - BMS),

- Pretvarača energetske elektronike,

- Transformatora i

- Konekcije na EES.

U ostrvskom režimu rada, frekvencija i napon ne predstavljaju više krute veličine, pa je često neophodno regulacijom uticati na njihove vrednosti. Stoga su u okviru posmatranog sistema realizovane dve upravljačke strukture:

- Kontrola regulacije frekvencije mreže koja je implementirana u BESS modelu kako bi se ispunio zahtev za održavanjem nominalne frekvencije $u$ sistemu i

- Upravljačka struktura naponskog invertora koja omogućava dvosmerni protok aktivne energije u sistemu.

\subsection{Upravljačke strukture izolovanog sistema sa priključenim uređajem za skladištenje energije}

$\mathrm{Na}$ osnovu trenutne vrednosti frekvencije u sistemu, sistem za skladištenje energije može raditi u dva režima, režimu punjenja i režimu pražnjenja, zahvaljujući dvosmernoj kontroli toka aktivne energije kroz invertor. Unutar dozvoljenog raspona promene frekvencije, koji se definiše u odnosu na nominalnu vrednost frekvencije, ne postoji potreba za angažovanjem sistema za skladištenje energije u EES. Međutim, kada frekvencija izađe izvan dozvoljenog opsega, sistem za skladištenje energije mora odgovoriti na odstupanja injektiranjem ili apsorbovanjem energije iz mreže. Za potrebe ovog istraživanja, definisani opseg promene frekvencije je $\pm 0.5 \mathrm{~Hz}$. To znači da kada je frekvencija veća od $50.5 \mathrm{~Hz}$, sistem za skladištenje treba da apsorbuje energiju iz EES-a, a kada je manja od $49.5 \mathrm{~Hz}$, sistem za skladištenje isporučuje energiju EES-u. 
Dinamička podrška za kontrolu frekvencije treba da bude u skladu sa sledećim zahtevima:

\section{- Vreme aktiviranja baterije:}

Dinamička rezerva mora se aktivirati neko vreme pre nego što se automatsko odsecanje opterećenja pokrene.

\section{- Trajanje isporuke:}

Dinamička rezerva mora se isporučivati sve dok se odstupanje snage u potpunosti ne nadoknadi, odnosno dok se ne dostigne određena vrednost frekvencije (što traje par sekundi). Ovo trajanje može se produžiti kako bi se podržao potpuni oporavak frekvencije.

\section{- Kraj isporuke:}

Kraj isporuke mora biti postepen kako bi se izbeglo stvaranje nagle neravnoteže u sistemu koji je već oslabljen.

Pored kontrole frekvencije, $\mathrm{u}$ modelu je implementirana upravljačka struktura bidirekcionog trofaznog naponskog invertora, kako bi se podržalo punjenje i pražnjenje baterije. To za posledicu ima da tok energije može biti ka jednosmernom kolu ili ka EES-u, dakle pretvarač obezbeđuje dvosmerni tok energije. Na slici 2 je prikazana šema upravljanja pomenutog trofaznog pretvarača koja je realizovana u sinhrono-rotirajućem koordinatnom sistemu. Transformacija u sinhrono-rotirajući koordinatni sistem omogućava raspregnuto upravljanje aktivnom i reaktivnom snagom, jer međusobno ortogonalne komponente struje po osama upravo određuju aktivnu (d osa) i reaktivnu (q osa) snagu [2]. U ovom radu je od značaja kontrola toka aktivne energije zbog svog neposrednog uticaja na frekvenciju izolovanog sistema, te će se stoga regulacija vršiti tako da se upravljačkom sklopu spram potreba mogu zadati različite referentne vrednosti direktne komponente struje $i_{d}{ }^{r e f}$. Vrednost referentne struje po $q$ osi $i_{q}{ }^{\text {ref }}$ će uvek biti jednaka nuli, jer se ne razmatra kontrola reaktivne snage.

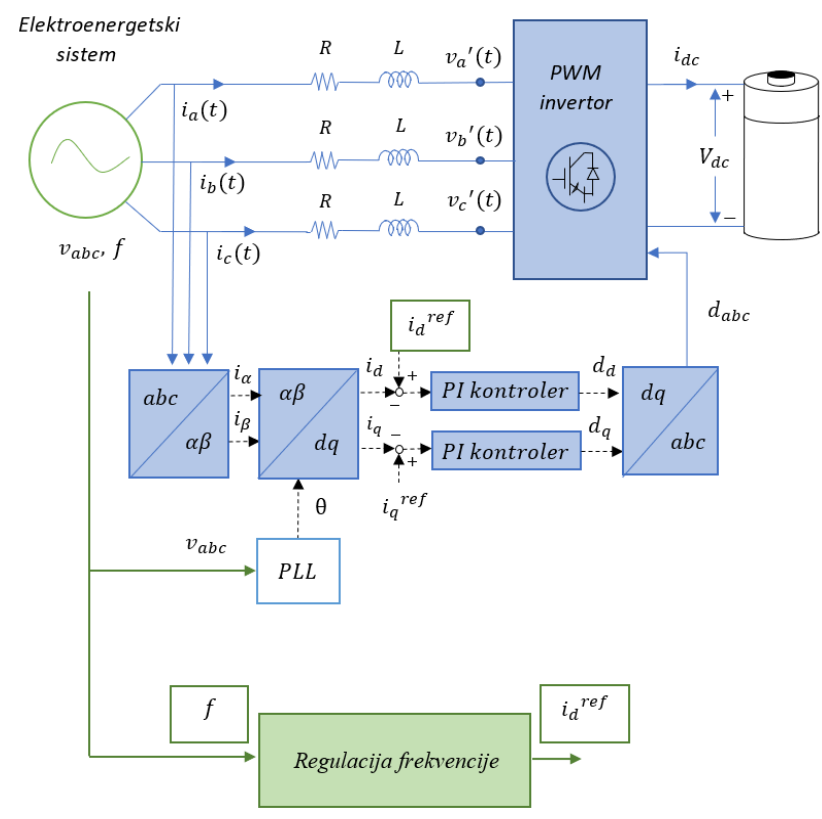

Slika 2. Upravljačka šema pretvarača

Matematičke jednačine koje opisuju sistem sa priključenim uređajem za skladištenje energije putem trofaznog naponskog invertora mogu se prikazati u trofaznom $a b c \mathrm{i}$ $d q$ domenu, respektivno:

$$
\begin{gathered}
L \cdot \frac{d}{d t}\left[\begin{array}{l}
i_{a} \\
i_{b} \\
i_{c}
\end{array}\right]=-R \cdot\left[\begin{array}{l}
i_{a} \\
i_{b} \\
i_{c}
\end{array}\right]+\left[\begin{array}{l}
v_{a} \\
v_{b} \\
v_{c}
\end{array}\right]-\left[\begin{array}{l}
v_{a}{ }^{\prime} \\
v_{b}{ }^{\prime} \\
v_{c}{ }^{\prime}
\end{array}\right], \\
\frac{d}{d t}\left[\begin{array}{l}
i_{d} \\
i_{q}
\end{array}\right]=\left[\begin{array}{cc}
\frac{-R}{L} & -\omega \\
\omega & \frac{-R}{L}
\end{array}\right] \cdot\left[\begin{array}{l}
i_{d} \\
i_{q}
\end{array}\right]+\left[\begin{array}{c}
\frac{V_{d}}{L} \\
\frac{V_{q}}{L}
\end{array}\right]-\left[\begin{array}{c}
\frac{d_{d}}{L} \\
\frac{d_{q}}{L}
\end{array}\right] V_{d c},
\end{gathered}
$$

gde $v_{a}^{\prime}, v_{b}{ }^{\prime}, v_{c}{ }^{\prime}$ predstavljaju napone na naizmeničnoj strani pretvarača, $R$ i $L$ sprežnu otpornost i induktivnost pretvarača, $v_{a}, v_{b}, v_{c}$ napone $\mathrm{i} i_{a}, i_{b}, i_{c}$ struje na mestu priključenja.

Do aktiviranja upravljačkog sistema dolazi usled nastalog poremećaja u mreži, koji izaziva premašenje dozvoljenog opsega promene frekvencije. Nakon toga, kontrolna petlja za regulaciju frekvencije detektuje promenu frekvencije $\mathrm{u}$ mreži i koristi $i_{d}^{\text {ref }}$ za regulisanje $i_{d} \mathrm{u}$ dvosmernom pretvaraču. Kao ulazi u PI regulatore se uvode signali greške dobijeni poređenjem ostvarene i zadate vrednosti struja po $d$ i $q$ osi. Uloga PI regulatora je da signal greške svede na nulu utičući na vrednost napona $v_{a b c}{ }^{\prime}$ na priključcima pretvarača. Upravljačke promenljive koje PI regulatori generišu na svojim izlazima $\left(d_{d}\right.$ i $\left.d_{q}\right)$ su referentne vrednosti napona u $d$ i $q$ osama, koje se nakon primene inverzne Blondelove transformacije, transformišu u željene faktore ispune prekidačkih komponenti $\left(d_{a b c}\right)$, koji se zatim pomoću impulsno-širinskog modulatora prevode $\mathrm{u}$ pobudne signale prekidača u pretvaraču. Time se postiže upravljanje stanjima prekidača $\mathrm{u}$ trofaznom naponskom invertoru, što za posledicu ima promenu vrednosti napona $v_{a b c}{ }^{\prime}$ na izlazu iz pretvarača. Generisanjem odgovarajućih vrednosti napona na izlazu iz pretvarača se postiže željeni tok energije. Naime, amplitudom i faznim stavovima generisanih napona se direktno utiče na uspostavljanje struja iz pretvarača ka mreži, ili obrnuto, čime se ujedno postiže i željeni tok energije.

\section{PRIMER PRIMENE UREĐAJA ZA SKLADIŠTENJE ENERGIJE U IZOLOVANOM EES MELILJE}

$\mathrm{U}$ cilju analize uticaja sistema za skladištenje energije $\mathrm{u}$ izolovanim EES, posmatrana je relativno mala mreža Melilje (Španija), koja se u velikoj meri oslanja na dizel generatore. Relativno niska inercija sistema i nedostatak povezanosti sa drugim električnim mrežama čine ovaj sistem veoma osetljivim na poremećaje.

Dinamičko ponašanje celokupnog sistema je modelovano u programskom paketu Matlab R2018a, kao što je prikazanao na slici 3. Rezultati simulacije dati u ovom radu zasnivaju se na BESS modelu od $1 \mathrm{MWh}$, sa maksimalnom snagom od \pm 1.75 MW. Bitno je napomenuti da je vreme odziva baterije ključni parametar dinamičke podrške. Vreme odziva određeno je brzinom kojom se isporučuje ili apsorbuje energija. Uobičajene vrednosti vremena odziva kreću se u opsegu od stotinu milisekundi do sekunde [2]. Parametri koji su korišćeni u modelu dati su u tabeli 1 . 


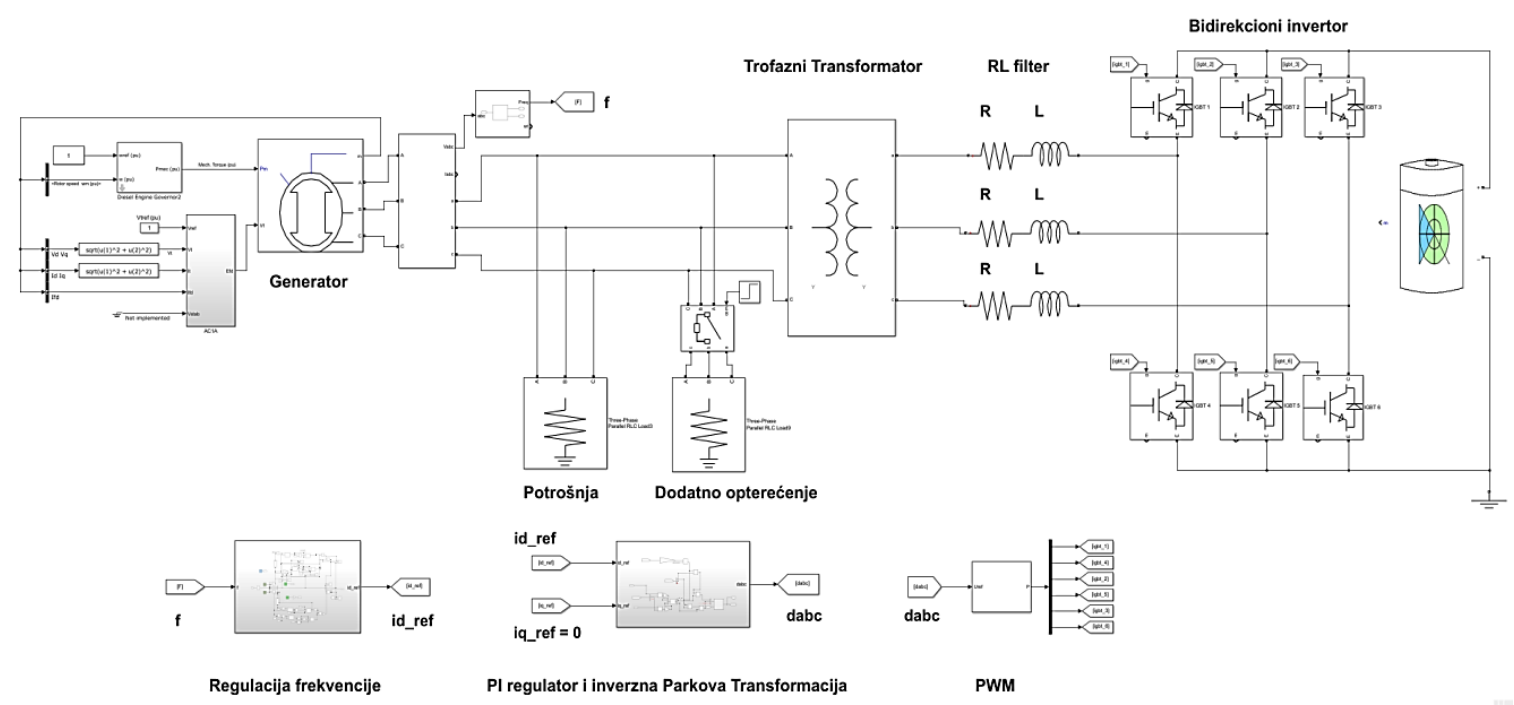

Slika 3. Model sistema sa priključenim uređajem za skladištenje energije u Matlab/Simulink-u

Tabela 1. Parametri koji su korišćeni u simulaciji

\begin{tabular}{ll}
\hline \hline \multicolumn{2}{c}{ Parametri baterije } \\
\hline Snaga & $0.5-1.75 \mathrm{MW}$ \\
Kapacitet skladištenja & $1 \mathrm{MWh}$ \\
Inicijalni SOC & $50 \%$ \\
Životni vek & 20 godina [2] \\
Vreme odziva & $100 \mathrm{~ms}$ \\
\hline \hline
\end{tabular}

\begin{tabular}{ll}
\hline \hline \multicolumn{2}{c}{ Parametri generatora } \\
\hline Konstanta inercije $H$ & $10 \mathrm{~s}$ \\
Snaga proizvodnje P & $14.6 \mathrm{MW}$ \\
\hline \hline
\end{tabular}

Na slici 4 je prikazana promena frekvencije sistema nakon naglog poremećaja od $4 \mathrm{MW}$, koji se dogodio u desetoj sekundi i delovanja prvog stepena sistema za odsecanje opterećenja koji se aktivira na $49 \mathrm{~Hz}$. $\mathrm{Na}$ istoj slici prikazana je i promena frekvencije kada su u sistemu priključene baterije različitih snaga. $U$ ovom radu, sistem za skladištenje energije radi kao impulsni izvor napajanja, snabdevajući svu svoju snagu tokom vrlo kratkog vremenskog perioda od nekoliko sekundi, kako bi se izbeglo delovanje sistema za odsecanje opterećenja. $\mathrm{Na}$ ovaj način se može podržati proizvodnja generatorskih jedinica u procesu regulacije frekvencije. Takođe, može se zapaziti da je maksimalni pad frekvencije nakon poremećaja značajno smanjen kao i vreme potrebno da EES dostigne ustaljeno stanje.

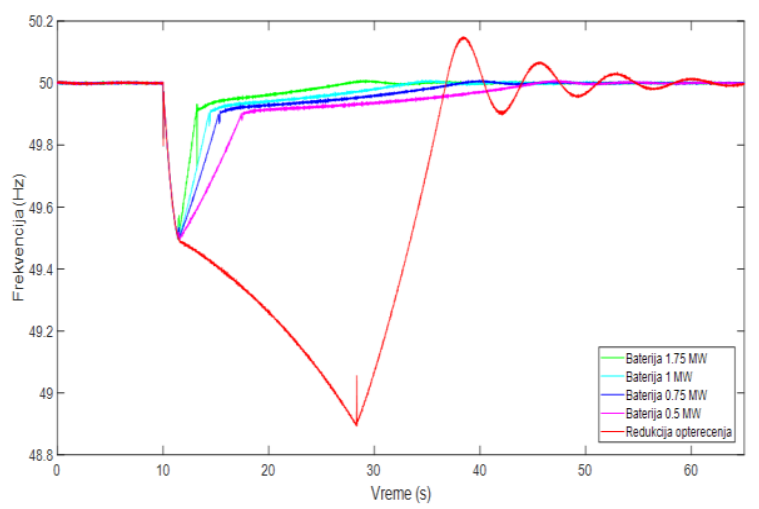

Slika 4. Promena frekvencije nakon naglog poremećaja $i$ delovanja sistema za odsecanje opterećenja (kriva crvene boje) $i$ delovanja baterija različitih snaga

\section{ZAKLJUČAK}

Pomoću odgovarajuće strategije kontrole aktivne snage sistemi za skladištenje energije mogu ublažiti promene frekvencije u sistemu, koje mogu biti uzrokovane prekidima proizvodnje ili naglim porastom opterećenja, čime se smanjuje potreba za automatskim odsecanjem opterećenja. Rezultati simulacije pokazuju da baterije mogu uspešno da obezbede potrebnu snagu zahvaljujući dvosmernoj kontroli aktivne energije koja je implementirana $u$ invertoru. Ovi rezultati pokazuju da uređaji za skladištenje energije u izolovanim EES doprinose rešavanju neravnoteža i bržem uspostavljanju stabilnog stanja u sistemu.

\section{LITERATURA}

[1] S.Homan, Investigating battery storage in combination with gas turbine generation for frequency regulation. Dostupno: https://static1.squarespace.com/

static/53ce14b9e4b03fc272f43709/t/59ede89bd0e6280748d 2c61d/1508763805109/Homan+Mini+Project+Final+Report .pdf.

[2] G.Delille et al., Dynamic Frequency Control Support by Energy Storage to Reduce the Impact of Wind and Solar Generation on Isolated Power System's Inertia, IEEE Trans. on Sustainable Energy, Vol. 3, No. 4, October 2012, pp. 931-939.

[3] M.M.Al-Mulla, N.C.Seeley, Distributed Generation Control In Islanded Industrial Facilities: A Case Study In Power Management Systems, PCIC Europe 2010, 15-17 June 2010, Oslo, Norway.

[4] A.Mohd et al., Challenges in Integrating Distributed Energy Storage Systems into Future Smart Grid; 2008 IEEE International Symposium on Industrial Electronics, 30 June2 July 2008, Cambridge, UK.

\section{Kratka biografija:}

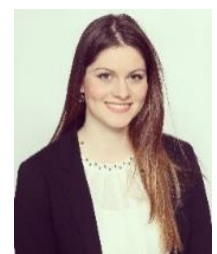

Vanja Stupar rođena je u Novom Sadu 1994. god. Diplomski rad na Fakultetu tehničkih nauka iz oblasti Elektrotehnike i računarstva - Elektroenergetski sistemi odbranila je 2017. god. Iste godine upisala je master studije. 